\title{
Transversus Thoracis
}

National Cancer Institute

\section{Source}

National Cancer Institute. Transversus Thoracis. NCI Thesaurus. Code C53180.

A muscle of the anterior thoracic wall originating on the posterior inferior portion of the sternum and the xiphoid process with insertion on the deep surface of costal cartilages 2-6; it functions to draw the ribs downward. 